\title{
Chapter 6 \\ Towards Equity in the Distribution of Ecosystem Services in Cities
}

\subsection{Introduction}

A major challenge for cities worldwide is achieving an equitable distribution of urban services (UN-Habitat 2016). Among the latter, urban ecosystem services (ES) are increasingly acknowledged for their role in contributing to health and wellbeing, hence promoted as a valid nature-based solution to many urban challenges (European Commission 2015). Yet, urban ecosystems, such as parks, trees, gardens, greenways, are heterogeneously distributed over space, and so are the ES they provide, which may cause inequality in the distribution of benefits to citizens (Ernstson 2013). Through urban planning, local administrations can manage the distribution of urban ecosystems and their services in a city, determining the number, location, and type of beneficiaries they reach (Kremer et al. 2013). However, this requires moving beyond general urban quality standards, such as per capita green space targets (Badiu et al. 2016; Kabisch et al. 2016), which do not capture details about the actual distribution of benefits across different areas and population groups (Larondelle and Haase 2013; Cortinovis et al. 2018).

McDermott and colleagues identified three dimensions of equity in relation to the local provision of ES, namely distributional equity, procedural equity, and contextual equity (McDermott et al. 2013). Distributional equity considers the allocation of benefits and costs associated to ES provision among stakeholders. Procedural equity looks at the level of participation and representation in decision-making processes that affect the provision of ES and related benefits. Contextual equity refers to the conditions that determine people's capability to participate to decisionmaking processes, as well as to access ES benefits, including physical, socioeconomic, and institutional barriers.

The vast literature on ES mapping is well equipped to assess distributional equity, possibly accounting for relevant contextual factors. A number of methods in the biophysical, socio-cultural, and economic domains exist to understand how supply 
and demand of ES, and related benefits and values, vary across space (Harrison et al. 2017; Santos-Martin et al. 2018). However, there are key elements that ES assessments need to consider, to be informative about the equitable distribution of ES. This chapter explores these elements, presents a case study application, and provides some conclusions on how planning can pursue equitable distribution of ES in cities.

\subsection{Elements to Assess Equity in the Distribution of ES}

Three spatial elements are important to understand the distributional equity of ES: supply (i.e., where ES services are produced), access (i.e., where and by whom ES are used), and demand (i.e., who needs ES). The first obvious step of the analysis consists in identifying where ES are actually supplied (Burkhard et al. 2012). To this end, many assessments rely on the spatial distribution of urban parks or public green areas as a proxy of the spatial distribution of ES supply in the city. In this way, however, they fail to account for the ES provided by other types of urban green areas, including private gardens (Lin et al. 2017), street trees and roadside vegetation (Mullaney et al. 2015; Säumel et al. 2016), community gardens (Camps-Calvet et al. 2015), or even brownfields and abandoned areas (Mathey et al. 2015; Pueffel et al. 2018).

Moreover, spatial analyses focused on the distribution of green areas in the city sometimes overlook the fact that different ecosystems supply different types of ES and with different levels of effectiveness (de Groot et al. 2010). As Daw et al. 2011 put it, assuming all green areas as "black boxes" providing ES - without being able to determine which ES are supplied, and to which level of effectiveness - is a poor starting point to address issues of equity. Worth of mention here is the fact that ES indicators should relate to an appropriate scale and resolution. While more and better data are generally available in cities compared to non-urban areas, informing urban planning decisions requires capturing changes with a high level of detail; hence, data availability may sometime represent a crucial barrier. To effectively capture ES supply and provide useful information for equitable distribution of ES, the assessment should consider all ecosystems in a city, not only public green spaces. In addition, it should provide disaggregated information about the different ES that are supplied, considering the extent to which different urban ecosystems contribute to the provision of each ES.

Comparing ES supply and demand in a spatially explicit way is a fundamental step to understand who benefits from which services (Burkhard et al. 2012). However, simple methods based on spatial overlays may overlook whether the potential beneficiaries can actually access the supply of ES (Schröter et al. 2012). Tallis and Polasky (2009) rightly refer to access to ES, which is different from access to ecosystems or to public green spaces. Areas of ES generation (service 
providing areas) do not always correspond to the areas where ES can be actually enjoyed (service benefitting areas) (Syrbe and Walz 2012). This is especially evident when the two areas are not physically connected, as in the case of food and raw materials that are traded across the globe, but it applies also for many regulating ES, including pollination, micro-climate regulation, flood protection, and noise mitigation (Fisher et al. 2009). Characterizing the flow of ES in terms of spatial relation between providing and benefitting areas is therefore instrumental to understand where the effects of planning actions are to be expected, hence to identify the associated "winners" and "losers" (Schröter et al. 2012).

While benefitting areas provide a good basis to measure access to ES, contextual factors restricting the ability of people to enjoy the benefits derived from ES should also be taken into account. These may include physical barriers, as well as formal (i.e., laws and regulations) and informal (e.g., social norms and cultural practices) institutional barriers that limit the access to ES. For example, land tenure can be used as a proxy to assess formal institutional access, since it provides a basis to discriminate between different potential users of public, common, and private spaces. Other aspects, including overcrowding, perception of safety, social bonds, and community cohesion are more difficult to capture, but can be relevant in determining who actually benefit from ES (Lee et al. 2015). In conclusion, to determine whether access to ES occurs or not, first, it is crucial to define the flow of ES and the spatial relation between providing and benefitting areas. Then, it is important to capture the possible physical and institutional barriers that may limit the access to benefitting areas, possibly identifying the affected population groups.

Concerning demand, a common practice in ES assessment is to consider it as equally distributed among all citizens, either by fixing standard thresholds (Kabisch and Haase 2014) or by relying on population density as a proxy (Baró et al. 2016), disregarding demographic and socio-economics differences among individuals and population groups. Yet, equity does not require everybody accessing the same types and amount of ES. On the opposite, it should be based on the analysis of the specific needs of each individual or population group (McDermott et al. 2013). Different people derive benefits from different ES, hence may express differentiated needs (Rodríguez et al. 2006). Understanding "who counts for equity" thus requires measuring the need for ES of different individuals and population groups by comparing their capabilities, the costs, benefits, risks, and opportunities associated to ES provision, as well as factoring variables like gender, age, and health status (Sen 2009).

Besides the "who", it is equally important to define "where" such demand is located (McDermott et al. 2013). Methods for mapping ES demand, i.e. describing how it varies across space, are manifold (Wolff et al. 2015). Applying them to a spatial analysis of the key variables that affect the demand of different individuals and population groups provides a disaggregated view that is essential to inform decision-making. Table 6.1 provides a summary of the elements described in this section. 
Table 6.1 Some recommendations for ES assessment addressing equity in the distribution of ES

\begin{tabular}{l|l|l}
\hline Supply & Access & Demand \\
\hline $\begin{array}{l}\text { (i) Consider all ecosystems in the } \\
\text { city, not only public green } \\
\text { spaces. }\end{array}$ & $\begin{array}{l}\text { (i) Consider access to ES, rather than to } \\
\text { ecosystems or public green spaces. }\end{array}$ & $\begin{array}{l}\text { (i) Consider the } \\
\text { "who" - the target } \\
\text { for demand. }\end{array}$ \\
\hline $\begin{array}{l}\text { (ii) Provide disaggregated } \\
\text { information about the supply of } \\
\text { different ES. }\end{array}$ & $\begin{array}{l}\text { (ii) Characterize the flow of ES in terms } \\
\text { of spatial relation between providing } \\
\text { and benefitting areas, direction, and } \\
\text { scale. }\end{array}$ & $\begin{array}{l}\text { (ii) Consider } \\
\text { where the demand } \\
\text { is located. }\end{array}$ \\
\hline $\begin{array}{l}\text { (iii) Specify to which extent } \\
\text { different ecosystems contribute } \\
\text { to the supply of different ES. }\end{array}$ & $\begin{array}{l}\text { (iii) Identify physical and institutional } \\
\text { barriers that may limit the access to ES } \\
\text { benefitting areas. }\end{array}$ & \\
\hline
\end{tabular}

\subsection{Application to a Study Area in the City of Trento}

A test application of the elements presented in the previous section has been conducted for different ES in the city of Trento (see Chap. 5 for more information about the city). The assessment focused on four urban ES relevant in the local context. Four 500-by-500 m sample areas were selected, roughly corresponding to four different residential neighbourhoods (see Fig. 6.1). The four sample areas are located in the central part of the city, where population density is higher and presence of public green spaces more limited than in the surrounding urban space, and are characterized by different socio-demographic conditions. The total extension of urban ecosystems, including trees, grass and shrubs, and bare soil in the four sample areas covers almost $300.000 \mathrm{~m}^{2}$, i.e. between one fourth and one third of the total surface. The average per capita amount of green space is around $50 \mathrm{~m}^{2}$.

To compare the sample areas, four regulating ES were selected, namely, carbon storage, air pollution removal, micro-climate regulation (cooling), and noise mitigation. The four ES differ significantly in terms of ecosystem functions that support the provision, spatial relation between providing and benefitting areas, and type of demand, hence they provide an interesting testbed to apply the elements described in the previous section.

\subsubsection{Assessing ES Supply}

The assessment of the supply of the selected ES was based on average values for different types of urban ecosystems retrieved from previous studies in urban contexts (McPhearson et al. 2013; Derkzen et al. 2015; Zardo et al. 2017). Table 6.2 summarizes the selected values harmonized with respect to four main land cover types; namely, (i) built-up and sealed, (ii) bare soil, (iii) grass and shrubs, (iv) trees and woodland. More in detail, carbon storage was estimated for coarse vegetation (i.e. trees and woodland), fine vegetation (i.e., grass and shrubs), and soil adopting 

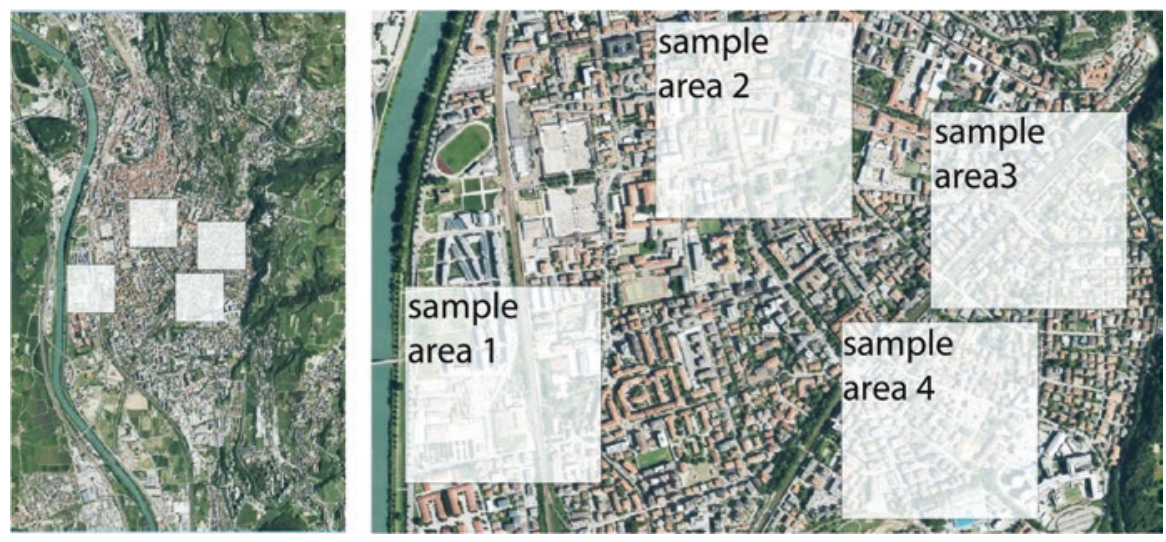

Fig. 6.1 The four selected sample areas in the city of Trento

Table 6.2 Average values for ES supply for different land cover types, in dimensional and dimensionless form

\begin{tabular}{|c|c|c|c|c|c|c|c|c|}
\hline \multirow{2}{*}{$\begin{array}{l} \\
\begin{array}{l}\text { Built-up and } \\
\text { sealed }\end{array}\end{array}$} & \multicolumn{2}{|c|}{ Carbon storage } & \multicolumn{2}{|l|}{$\begin{array}{l}\text { Air pollution } \\
\text { removal }\end{array}$} & \multicolumn{2}{|c|}{$\begin{array}{l}\text { Micro-climate } \\
\text { regulation }\end{array}$} & \multicolumn{2}{|l|}{ Noise reduction } \\
\hline & - & 0 & - & 0 & - & 0 & - & 0 \\
\hline Bare soil & $8.2 \mathrm{~kg} / \mathrm{m}^{2}$ & 5.3 & - & 0 & $1.2^{\circ} \mathrm{C}$ & 3.3 & - & 0 \\
\hline $\begin{array}{l}\text { Grass and } \\
\text { shrubs }\end{array}$ & $8.4 \mathrm{Kg} / \mathrm{m}^{2}$ & 5.4 & $1.12 \mathrm{~g} / \mathrm{m}^{2} /$ year & 4 & $1.2^{\circ} \mathrm{C}$ & 3.3 & $\begin{array}{l}0.375 \\
\mathrm{Db}(\mathrm{A}) / 100 \mathrm{~m}^{2}\end{array}$ & 1.8 \\
\hline $\begin{array}{l}\text { Trees and } \\
\text { woodland }\end{array}$ & $15.5 \mathrm{~kg} / \mathrm{m}^{2}$ & 10 & $2.73 \mathrm{~g} / \mathrm{m}^{2} /$ year & 10 & $3.6^{\circ} \mathrm{C}$ & 10 & $2 \mathrm{Db}(\mathrm{A}) / 100 \mathrm{~m}^{2}$ & 10 \\
\hline
\end{tabular}

the same average values applied by McPhearson et al. (2013) to the city of New York. The same approach was used to assess air pollution removal, focusing on PM10 deposition on grass and woody vegetation (McPhearson et al. 2013). Based on Derkzen et al. (2015), values for air pollution removal where doubled for green areas located within a 50-m buffer from streets to account for the higher concentration of PM10 that increases the deposition flux. Cooling was assessed following the approach described in Chap. 4. Finally, noise reduction was assessed by adopting the values proposed by Derkzen et al. (2015). For each ES, the values were then converted into dimensionless scores ranging from 0 to 10 , where 10 corresponds to the value of the best-performing land cover type.

Operationally, the first step to map the supply of ES consisted of the visual inspection of an aerial image to identify the main land cover types in the four sample areas, followed by screen digitising in a GIS. The land-cover information was then combined with the standardized values from Table 6.2 to obtain supply maps for each ES. To get an overall indicator of ES supply in each sample area, the 
surface of each land-cover type was multiplied by the corresponding standardized value, and then the contributions of the different land cover types were summed. Finally, the result was divided by the total surface of the sample area to obtain an overall score ranging from 0 to 10 , which measures the supply of each ES in each sample area.

Figure 6.2 shows the results of the supply analysis. Overall, Sample area 3 shows the highest supply score for three of the four analysed ES, namely: air pollution removal, cooling, and noise reduction. For carbon storage, the best performance is represented by Sample area 1. Noteworthy is that Sample area 3 performs better despite the lower amount of green areas compared to Sample area 1. Furthermore, the performance of each sample area varies depending on the ES that is being considered. This shows the importance of the typology of green areas in determining the supply of ES, and the potential bias that aggregated indicators (such as per-capita green area) can introduce in the representation of the equitable distribution of ES.

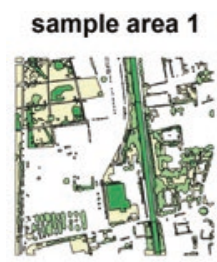

supply score $2.7 / 10$

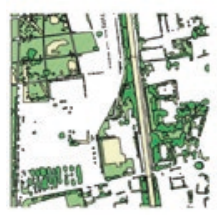

supply score $1.6 / 10$

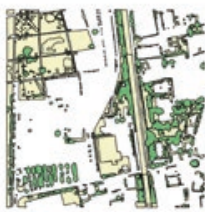

supply score $2.1 / 10$

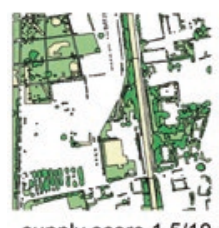

supply score $1.5 / 10$ sample area 2

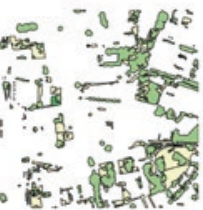

supply score $1.6 / 10$

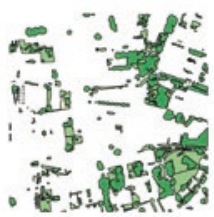

supply score $1.4 / 10$

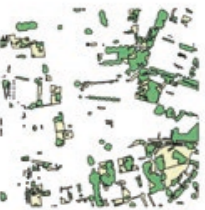

supply score $1.6 / 10$

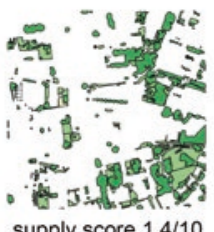

sample area 3

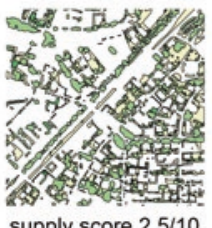

supply score $2.5 / 10$

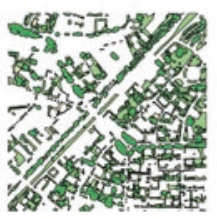

supply score $2.2 / 10$
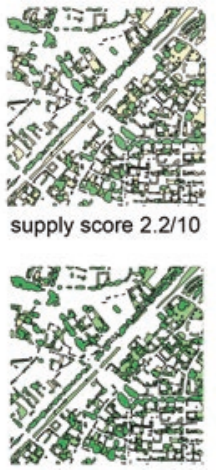

supply score $1.9 / 10$ sample area 4

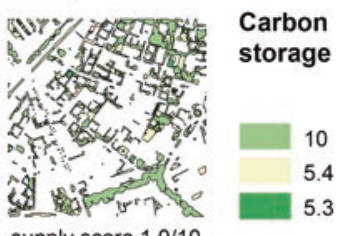

Air pollution removal

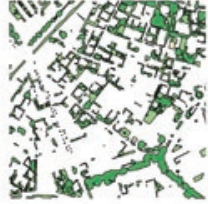

supply score $0.9 / 10$

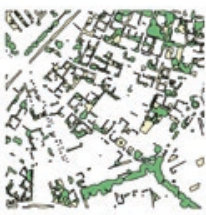

supply score $1.5 / 10$

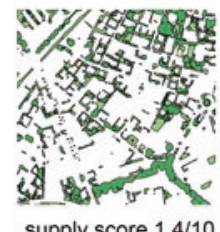

Noise reduction

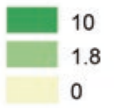

Fig. 6.2 Assessment of the supply of the four selected ES in the four sample areas 


\subsubsection{Assessing Access to ES}

The assessment of the access to the four selected ES considered two main aspects, mentioned in Table 6.1. First, service benefitting areas were identified based on the flow of ES, by considering the specific spatial relation between providing and benefitting areas, direction, and scale that characterize each ES. Second, the presence of physical or institutional barriers to access were verified in each case. The relevant spatial characteristics of ES flow, the potential barriers to access, and the method adopted is presented in Table 6.3.

In the case study, given the small size of the samples, it was assumed that all benefitting areas are physically accessible, i.e., within walking distance from households (Kabisch and Haase 2014). For the ES to which institutional access might be relevant, land tenure was used as a proxy to restrict the analysis to benefitting areas accessible to all residents. Hence, only public areas are considered as possible places for enjoying the benefits of cooling and noise reduction, while carbon storage and air pollution removal are not affected by any limitation. The overall access score for each sample area was obtained by applying the same procedure used for the

Table 6.3 Relevant spatial characteristics of ES flow, potential barriers to access, and method adopted to assess access for the four selected ES

\begin{tabular}{l|l|l}
\hline & $\begin{array}{l}\text { ES flow and characteristics of } \\
\text { benefitting areas }\end{array}$ & Method \\
\hline $\begin{array}{l}\text { Carbon } \\
\text { storage }\end{array}$ & $\begin{array}{l}\text { Global and non-proximal, } \\
\text { equally distributed across the } \\
\text { city; access to specific areas is } \\
\text { not required to benefit from the } \\
\text { ES }\end{array}$ & $\begin{array}{l}\text { All sample areas are assigned the same access } \\
\text { score calculated as the average of the supply } \\
\text { scores of the four sample areas. The score is } \\
\text { considered as homogeneously distributed over } \\
\text { the whole study area. }\end{array}$ \\
\hline $\begin{array}{l}\text { Air } \\
\text { pollution } \\
\text { removal }\end{array}$ & $\begin{array}{l}\text { Local (district) and non- } \\
\text { proximal, evenly distributed } \\
\text { across the neighbourhood; } \\
\text { access to specific areas is not } \\
\text { required to benefit from the ES }\end{array}$ & $\begin{array}{l}\text { For each sample area, the score calculated in the } \\
\text { supply analysis is used. The score is considered } \\
\text { as homogeneously distributed over each sample } \\
\text { area. }\end{array}$ \\
\hline $\begin{array}{l}\text { Micro } \\
\text { climate } \\
\text { regulation }\end{array}$ & $\begin{array}{l}\text { Local (site/block) and proximal, } \\
\text { the distribution is considered } \\
\text { omnidirectional with benefitting } \\
\text { areas up to some hundreds } \\
\text { meters all around the area. } \\
\text { Access to defined benefitting } \\
\text { areas is required to benefit from } \\
\text { the ES. }\end{array}$ & $\begin{array}{l}\text { For green areas with an extension of less than } \\
\text { up the estimated cooling effect is perceivable } \\
\text { up distance of about 100 m from the site } \\
\text { Shashua-Bar and Hoffman (2000). Those areas } \\
\text { are assigned a score that is half of that of the } \\
\text { green area itself. Moreover, to consider the local } \\
\text { contribution of shading by trees, a buffer of 5 m } \\
\text { around the canopies is added with the same } \\
\text { score as the supply score assigned to trees. }\end{array}$ \\
\hline $\begin{array}{l}\text { Noise } \\
\text { mitigation }\end{array}$ & $\begin{array}{l}\text { Local (site) and proximal, the } \\
\text { distribution is directional with } \\
\text { benefitting areas up to some tens } \\
\text { meters from the noise source. } \\
\text { Access to defined benefitting } \\
\text { areas is required to benefit from } \\
\text { the ES. }\end{array}$ & $\begin{array}{l}\text { Benefitting areas are identified by creating a } \\
50 \text { m-buffer from the streets and their score is set } \\
\text { as half of the supply score of the green area that } \\
\text { provides the service Derkzen et al. (2015). }\end{array}$ \\
\hline
\end{tabular}


supply, resulting in a normalized score ranging from 0 to 10 . The final access score also incorporates the assessment of ES supply conducted in the previous step, hence the access score could also be interpreted as a 'reduced' supply score that accounts for issues related to the spatial distribution of service benefitting areas and their accessibility, when relevant to the specific ES under investigation.

The results of the access analysis vary depending on the ES. For carbon storage and air pollution removal, which are assumed to be equally distributed over the sample areas, no further spatial analysis is needed. For carbon storage, the same score is assigned to all areas, while for air pollution removal a score equal to the supply score is used to characterise the different sample areas. For the ES that produce local benefitting areas characterised by proximity to the providing areas, the results of the access analysis are shown in Fig. 6.3. For both micro-climate regulation and noise reduction, the ranking of the sample areas based on the access score is different than the ranking based on the supply score

\subsubsection{Assessing ES Demand}

According to Wolff et al. (2015), depending on the type of ES, the demand can be assessed either based on direct use, or based on preferences for a desirable level of ES supply. In the case of regulating services, many assessments adopts the latter method, defining the desirable level through indicators of vulnerability (Wolff et al. 2015). Here we refer to Kazmierczak (2012), who identified four main vulnerable groups based on criteria of poverty, diversity (presence of foreigners), and age, specifically distinguishing children (0-4 years old) and elderly (above 65 years old). In the case study, the poverty indicator was not considered due to the lack of disaggregated spatial data. The other three criteria were assessed based on census data provided by the local administration. The number of residents, children, elderly, and

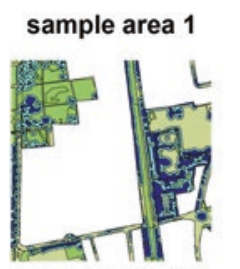

access score $1.5 / 10$

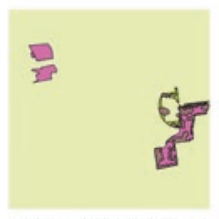

access score $1.5 / 10$
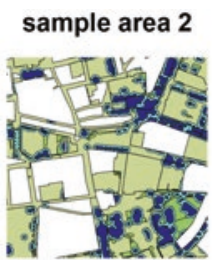

access score 2.2/10

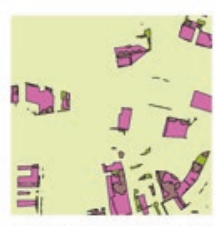

access score $0.9 / 10$ sample area 3

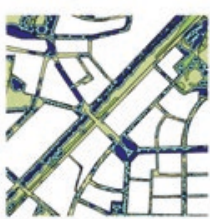

access score $2.6 / 10$

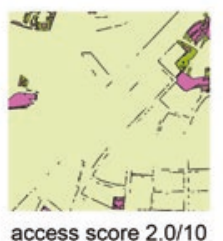

sample area 4

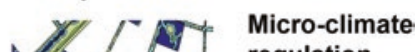

regulation
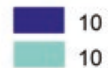

3.3

1.6

access score $0.3 / 10$

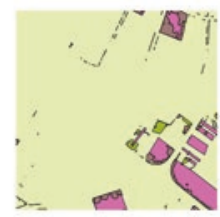

Noise reduction

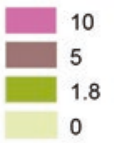

access score $0.5 / 10$

Fig. 6.3 Assessment of access to two proximity-dependent ES in the four sample areas 
foreigners for each census block was linked to the map by considering all groups as evenly distributed on the surface covered by the footprint of residential buildings. Noteworthy, overlapping of vulnerabilities (e.g. an old person that is also a foreigner) were not taken into account; instead, any vulnerable was counted as one unit assuming that an individual that is both old and foreigner and the presence of one old person and one foreigner would raise equally the vulnerability of the neighbourhood. The overall score of ES demand was obtained by normalizing the number of vulnerable individuals in the sample areas on a scale between 0 and 10 . The distribution of vulnerable individuals is almost proportional to the distribution of the population density, i.e. the area with the highest population density is also the area with highest number of vulnerable individuals.

\subsubsection{Combining Information of Supply, Access and Demand}

Taken singularly, the results of the analyses described in the previous sub-sections can be used to identify hotspots in the city where supply, access and demand for ES are particularly high. The supply, access and demand scores can also be aggregated to unveil, for example, mismatches between demand and supply (Ortiz and Geneletti 2018). As an example of aggregation, we proposed a combined indicator based on the scores of access and demand analysis, given the former also include the supply score. Operationally, for each ES and each sample area, the access score was divided by that of demand, so that higher values correspond to better performances. The combined indicator allows ranking different areas of the city, based on a comparison between the existing demand for ES, and their actual availability for the citizens. Hence, it can provide more information with respect to considering only supply and demand. As an illustration, Fig. 6.4 compares this indicator with assessments based on supply only, and the ratio between supply and demand (without considering access). The comparison focuses on cooling and noise reduction, two examples of ES for which access is a relevant factor to consider in the assessment.
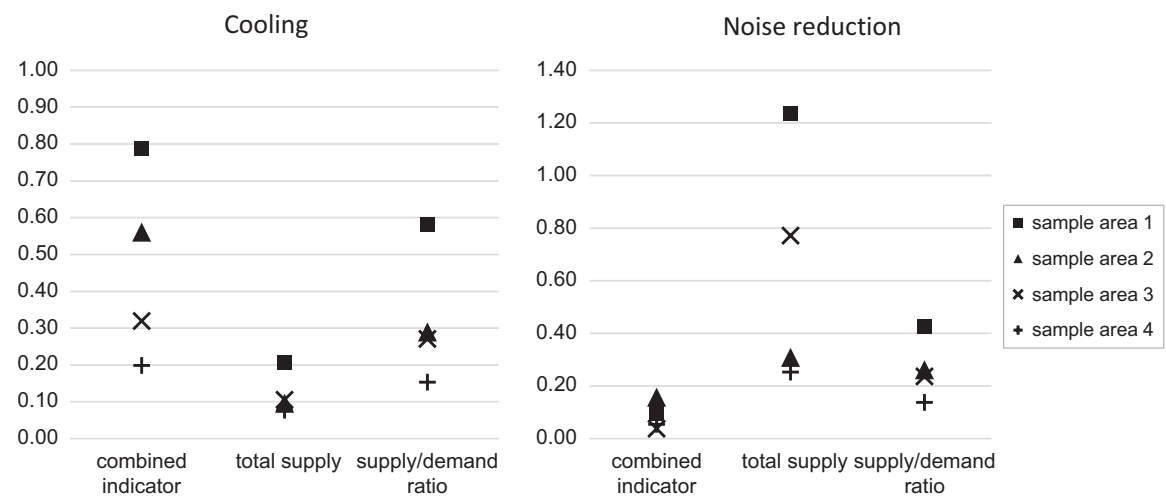

Fig. 6.4 Comparison of the combined indicators with the total supply and the ratio between supply and demand in the four sample areas for cooling (left) and noise reduction (right) 


\subsection{Conclusions}

An equitable distribution of resources, and more specifically of ES, is one of the key elements in the purse of equity, and sustainability. ES assessments that investigate the distribution of ES can play an important role in addressing equity issues in urban planning. The concept of ES represents a very useful tool since it allows understanding and quantifying how ecosystems provide services and spatially defining the relationship between their structure, functions, and the related benefits at a suitable scale (Braat and de Groot 2012). In this chapter, we suggest that ES assessments need to capture information about the supply, access, and demand of services in a city, in order to provide planners with useful information on the degree of equity in the distribution of ES.

The approach described in the case study application present limitations. Firstly, access to ES was estimated in a simplified way, reflecting the limited contributions on this topic found in the literature. There is a need for studies that go more in depth in unveiling, and mapping all the factors that may play a role in determining how ES are accessed by beneficiaries. Secondly, demand was estimated by considering only few categories of vulnerable individuals. Other socio-economic and cultural factors (e.g., housing conditions) could be added to improve the analysis, exploring the complexity of the demand for regulating ES in cities, and distinguishing among different groups of beneficiaries associated to different ES. Thirdly, the assessment of supply was also based on one single indicator for each ES. Using multiple indicators could provide a better picture of different types of supply, reflecting for example different potential uses by beneficiaries.

In conclusion, the potential of applying holistic approaches to the investigation of distribution of ES, which include biophysical, as well as socio-economic considerations, cannot be ignored. Despite using disaggregated data and complex assessments can be costly and time-consuming (Gómez-Baggethun and Barton 2013), there is a need to keep on walking this path to improve the outcome of planning processes.

Open Access This chapter is distributed under the terms of the Creative Commons Attribution 4.0 International License (http://creativecommons.org/ licenses/by/4.0/), which permits use, duplication, adaptation, distribution and reproduction in any medium or format, as long as you give appropriate credit to the original author(s) and the source, a link is provided to the Creative Commons license and any changes made are indicated.

The images or other third party material in this chapter are included in the work's Creative Commons license, unless indicated otherwise in the credit line; if such material is not included in the work's Creative Commons license and the respective action is not permitted by statutory regulation, users will need to obtain permission from the license holder to duplicate, adapt or reproduce the material. 